\title{
URINE ALBUMIN-TO-CREATININE RATIO AND ESTIMATED GLOMERULAR FILTRATION RATE IN MATCHED GROUPS OF TYPE 2 DIABETES MELLITUS PATIENTS RECEIVING METFORMIN AND METFORMIN-SULFONYLUREA
}

\author{
RANI SAURIASARI*, HANIFA ARISTIA, AZIZAHWATI
}

Clinical Pharmacy Division, Faculty of Pharmacy, Universitas Indonesia, Depok, Indonesia. Email: rani@farmasi.ui.ac.id

Received: 26 September 2019, Revised and Accepted: 17 December 2019

\section{ABSTRACT}

Objective: Renal disease complications in type 2 diabetes mellitus patients are characterized by progressive urinary albumin excretion and decreased glomerular filtration. The drugs most commonly prescribed as antidiabetic therapy in Indonesia are metformin and sulfonylurea. It is still unclear whether the effect of metformin-sulfonylurea on kidney is different from that of metformin monotherapy.

Methods: We compared the effectiveness of metformin monotherapy and metformin-sulfonylurea combination to the urine albumin-to-creatinine ratio (UACR) and estimated glomerular filtration rate (eGFR) as renal function parameters. Study subjects were patients on either of these drug regimens for at least 1 year. We collected 88 samples from type 2 diabetes mellitus patients (37 patients on metformin and 51 on metforminsulfonylurea). The patients fasted for $8 \mathrm{~h}$ before urine and blood collection for UACR and eGFR analysis. We measured the eGFR using the chronic kidney disease epidemiology collaboration (CKD-EPI) equation, serum creatinine, and urine creatinine by colorimetric enzymatic assay, and urine albumin by immunoturbidimetry.

Results: The eGFR level in the metformin and metformin-sulfonylurea groups was within the normal range, but lower in the metformin group $(79.59 \pm 2.81)$ than in the metformin-sulfonylurea group $(87.82 \pm 2.82)(\mathrm{p}=0.018)$. In addition, hyperfiltration cases were more frequent in metforminsulfonylurea group $(\mathrm{p}=0.029)$. The UACR in patients taking metformin-sulfonylurea $(177.95 \pm 60.92)$ was higher than that in the metformin group $(49.58 \pm 14.19)$ but the difference between them was not significant $(p=0.099)$.

Conclusion: Metformin monotherapy was associated with a lower frequency of hyperfiltration and lower UACR level compared to metforminsulfonylurea combination.

Keywords: Metformin, Sulfonylurea, Estimated glomerular filtration rate, Urine albumin-to-creatinine ratio.

(c) 2020 The Authors. Published by Innovare Academic Sciences Pvt Ltd. This is an open access article under the CC BY license (http://creativecommons. org/licenses/by/4. 0/) DOI: http://dx.doi.org/10.22159/ijap.2020.v12s1.FF056

\section{INTRODUCTION}

Diabetes mellitus is the leading cause of death among patients with endstage renal disease. Uncontrolled hyperglycemia in diabetic mellitus patients continuously exposes the body to high glucose levels. This condition triggers the development of complications in body organs, including the kidney [1]. In diabetes mellitus patients, renal disease complications are characterized by progressive urinary excretion through urine and a decreased glomerular filtration rate [2]. These patients are advised to have their kidney function monitored by urine albumin-to-creatinine ratio (UACR) and estimated glomerular filtration rate (eGFR) measurement. To prevent the progression of diabetic kidney disease, an early diagnosis is essential [3].

Glycemic control can prevent and delay the risk of diabetic nephropathy. In Indonesia, managing type 2 diabetes mellitus involves applying a healthy lifestyle (medical nutrition therapy and physical activity) and pharmacological therapy using antidiabetic medication. Antidiabetic medication may be given as a mono- or combination therapy. In primary health care, the most commonly used drug is metformin, either in monotherapy or in combination with sulfonylurea [4]. Previously, metformin use was contraindicated due to the susceptibility to lactic acidosis in type 2 diabetes mellitus patients with chronic kidney disease (CKD). In 2016, The U.S. Food and Drug Administration modified the recommendation of metformin use in patients with "mild to moderate renal dysfunction" (stage 1 to 3a). Some studies showed that, apart from metformin's capacity to treat type 2 diabetes, it is a potential nephroprotective agent [5].
However, to understand metformin's nephroprotective nature, many experimental and clinical studies are still required [5]. It is reported that metformin-sulfonylurea combination has an antioxidant effect [6]. Conversely, metformin can reduce the risk of decreased renal function compared to a combination of metformin-sulfonylurea [7]. Meanwhile, another study found patients taking metformin-sulfonylurea to be at lower risk of kidney failure compared to those taking metformin [8]. Therefore, this study aimed to analyze UACR and eGFR as renal function parameters in patients taking metformin or a metforminsulfonylurea combination.

\section{MATERIALS AND METHODS}

We designed this study as cross-sectional with consecutive sampling. We obtained data from blood and urine sample analyses and other information from a validated questionnaire. We performed sampling at Pasar Minggu Community Health Center between March 2018 and May 2018. We conducted the sample analyses at Prodia Laboratory, Depok, between March 2018 and May 2018. We recruited type 2 diabetes mellitus patients who were receiving treatment at Pasar Minggu Community Health Center and taking metformin or a metforminsulfonylurea combination for at least 1 year. Inclusion criteria were patient aged $>18$ years and fasting at least $8 \mathrm{~h}$ before sampling. Exclusion criteria were patient with severe anemia and hematuria. We registered this study in the Ethics Committee of Faculty of Medicine, University of Indonesia (No. 0163/UN2.F1/ETIK/2018). Before sampling, we received informed consent from patients and recorded their basic characteristics using a questionnaire. 
We instructed the patients to fast for at least $8 \mathrm{~h}$ before collecting urine and blood samples. We sampled urine by asking patients to collect $30 \mathrm{~mL}$ of their first morning urine. Blood sampling was performed by a certified phlebotomist. We labeled the urine and blood samples, stored them in a cool box, and delivered them to Prodia Clinical Laboratory for UACR and eGFR analysis. Blood samples for HbA1c analysis were taken from the patients' fingertips. HbA1c analysis was performed using Afinion ${ }^{\mathrm{TM}}$ AS100 analyzer (Alere, USA). We measured UACR by comparing urine albumin concentration with urine creatinine concentration. We measured urine albumin using the immunoturbidimetry principle and urine creatinine using the enzymatic colorimetric method. We converted the creatinine in the sample by a series of enzymatic reactions involving creatininase, creatinase, and sarcosine to form a peroxide that oxidizes 4-aminophenol, and then forms a color complex (quinone). The red absorbance, produced by quinone, at $545 \mathrm{~nm}$ is proportional to the creatinine concentration in the sample. We measured eGFR by determining serum creatinine with the enzymatic colorimetric method. We defined the eGFR's value based on the CKD epidemiology collaboration (CKD-EPI) equation. We analyzed data using SPSS (IBM 2.0) software. We considered data to be significant if $\mathrm{p}<0.05$.

\section{RESULTS AND DISCUSSION}

This study included 88 patients, 37 of whom were taking metformin, and the other 51 patients were taking metformin-sulfonylurea combination. We found no significant differences in any basic characteristics (Table 1).
There were no differences in age and proportion of female and male samples in the two groups. The mean of body mass index in the two groups was included in moderate criteria $\left(18.50-24.99 \mathrm{~kg} / \mathrm{m}^{2}\right)$. Body mass index can be affected by diet and exercise activities [9]. The proportions of patients consuming anti-hypertensive drugs and antihyperlipidemia drugs were also not significantly different (Table 1). The use of antihypertension drugs is common in diabetic patients because diabetes and hypertension contribute along similar pathways such as the sympathetic nervous system, the renin-angiotensin-aldosterone system, oxidative stress, adipokines, insulin resistance, and PPARs [10]. These pathways interact and influence each other and may even cause a vicious cycle. Metabolic syndrome causes hypertension and diabetes [10]. Diabetic patients commonly have high cholesterol levels, especially those who cannot control their diets. To decrease the cholesterol levels, doctors often prescribe antihyperlipidemia drugs if lifestyle modification is inadequate. Blood pressure, both systole and diastole, remained within the normal range in both groups. Urine creatinine level in patients taking a metformin-sulfonylurea combination was lower those in patients taking metformin but not significantly different (Table 2). However, urine creatinine level in both groups remained within the normal range. On the other hand, the urine albumin level in both groups exceeded the normal range. The urine albumin levels in patients taking a metforminsulfonylurea combination $(177.95 \pm 60.92)$ were much higher than those in patients taking metformin (49.58 \pm 14.19$)$, but not significantly different. Higher albumin levels in patients taking sulfonylurea were also reported by Hung et al. [7]. In their cohort of veterans with

Table 1: Basic characteristics of study subjects

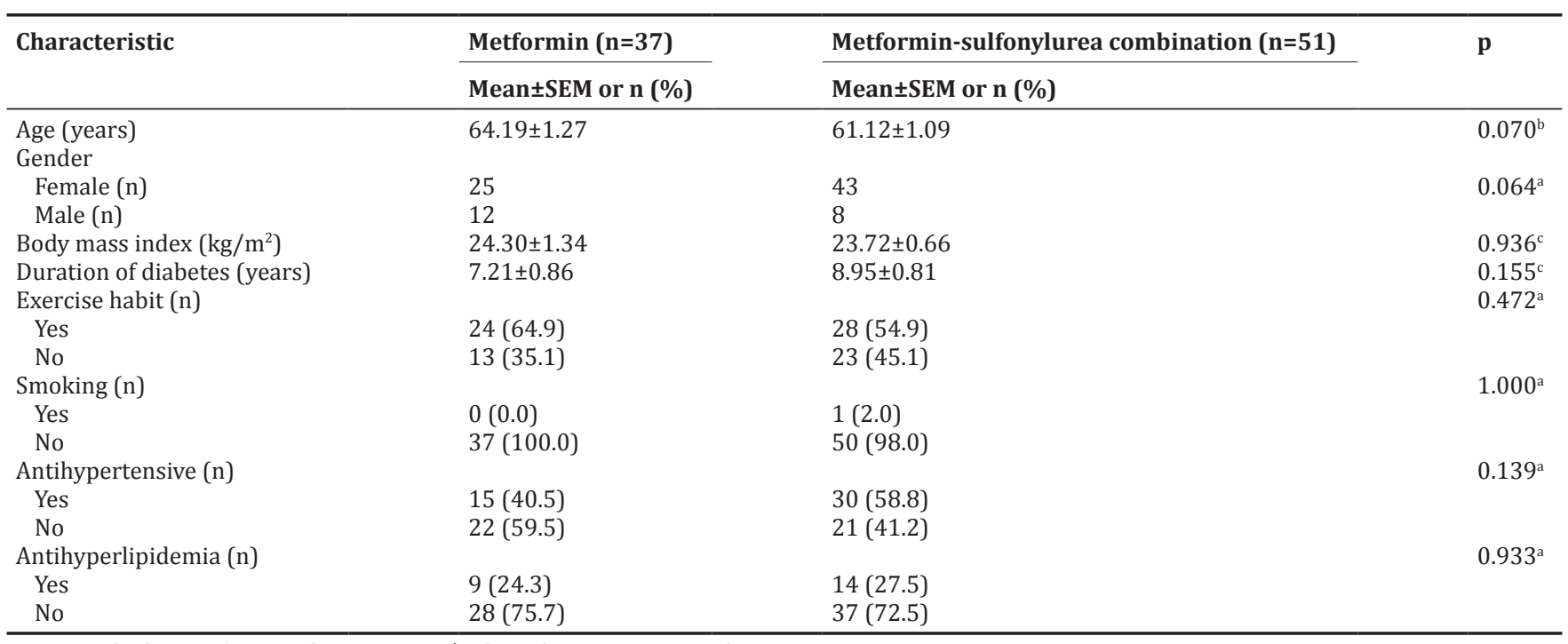

SEM: Standard error of mean; ${ }^{\mathrm{C} C h i-S q u a r e ~ T e s t ; ~}{ }^{\mathrm{b} I n d e p e n d e n t ~ t-t e s t ; ~}{ }^{\mathrm{c}}$ Mann-Whitney Test

Table 2: Clinical characteristics of study subject

\begin{tabular}{|c|c|c|c|}
\hline \multirow[t]{2}{*}{ Characteristic } & \multirow{2}{*}{$\begin{array}{l}\text { Metformin }(n=37) \\
\text { Mean } \pm \text { SEM or } n(\%)\end{array}$} & \multirow{2}{*}{$\begin{array}{l}\text { Metformin-sulfonylurea combination }(n=51) \\
\text { Mean } \pm \text { SEM or } n(\%)\end{array}$} & \multirow[t]{2}{*}{$\mathbf{p}$} \\
\hline & & & \\
\hline \multicolumn{4}{|l|}{ Blood pressure } \\
\hline Diastolic (mmHg) & $76.22 \pm 0.98$ & $77.06 \pm 0.94$ & $0.636^{b}$ \\
\hline $\mathrm{HbA1c}(\%)$ & $7.75 \pm 0.22$ & $9.04 \pm 0.25$ & $0.001^{\mathrm{b}^{*}}$ \\
\hline Urine albumin (mg/L) & $28.51 \pm 6.45$ & $105.72 \pm 39.06$ & $0.315^{b}$ \\
\hline Urine creatinine $(\mathrm{mg} / \mathrm{dL})$ & $81.93 \pm 11.20$ & $65.11 \pm 5.81$ & $0.559^{b}$ \\
\hline Serum creatinine $(\mathrm{mg} / \mathrm{dL})$ & $0.87 \pm 0.04$ & $0.76 \pm 0.03$ & $0.006^{\mathrm{b}^{*}}$ \\
\hline UACR $(\mathrm{mg} / \mathrm{g})$ & $49.58 \pm 14.19$ & $177.95 \pm 60.92$ & $0.099^{b}$ \\
\hline eGFR $\left(\mathrm{mL} / \mathrm{min} / 1.73 \mathrm{~m}^{2}\right)$ & $79.59 \pm 2.81$ & $87.82 \pm 2.82$ & $0.018^{\mathrm{b}^{*}}$ \\
\hline \multicolumn{4}{|l|}{ eGFR $(n=86)$} \\
\hline $\mathrm{eGFR} \geq 90 \mathrm{~mL} / \mathrm{min} / 1.73 \mathrm{~m}^{2}$ & $13(35.1)$ & $30(61.2)$ & $0.029^{\mathrm{a}^{*}}$ \\
\hline $\mathrm{eGFR}<90 \mathrm{~mL} / \mathrm{min} / 1.73 \mathrm{~m}^{2}$ & $24(64.9)$ & $19(38.8)$ & \\
\hline
\end{tabular}

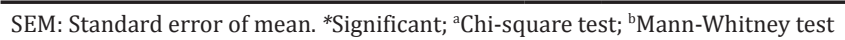


type 2 diabetes, kidney function declined faster among initiators of sulfonylureas compared to metformin [7]. A lower risk of kidney function decline or death was associated with metformin initiation compared to sulfonylureas, independent of changes in body mass index, systolic blood pressure (SBP), and glycated hemoglobin over time [7].

In this study, we showed that glycated hemoglobin (HbA1c) levels in the metformin-sulfonylurea group were much higher compared to metformin $(\mathrm{p}=0.001)$ (Table 2). In both groups, the HbA1c level was more than $7 \%$ - still below the target for diabetes mellitus treatment (Table 2). HbA1c has a strong correlation with microalbuminuria development in patients with type 2 diabetes mellitus [11]. This means that the effectiveness of metformin and a metformin-sulfonylurea combination was still inadequate in this study, probably because patients do not comply with the prescribed dietary and lifestyle restrictions [12].

The serum creatinine level showed statistically significant differences in the two groups $(p=0.006)$. However, the clinical serum creatinine level of these groups did not differ greatly and still within the normal range: $0.7-1.2 \mathrm{mg} / \mathrm{dL}$ for male and $0.5-0.9 \mathrm{mg} / \mathrm{dL}$ for female. There was no significant UACR difference $(\mathrm{p}=0.099)$ between groups. These results agree with a previous study [13]. The UACR in both groups was categorized as microalbuminuria in the $30-300 \mathrm{mg} / \mathrm{g}$ range. Although the difference was not statistically significant, the UACR in patients taking a metformin-sulfonylurea combination was higher than that in the metformin group. Kumar et al. (2019) reported that metformin monotherapy treatment (MMT) has shown a very good improvement in the progressive reductions in the levels of glycemic parameters (FPG, PPPG, and HbA1c) as well as maintaining the functions of kidney to near normal before and after 6 and 12 months of MMT [14].

Despite the potency of metformin monotherapy, this result may be influenced by high levels of HbA1c in the metformin-sulfonylurea combination patients. Glucose fluctuations may cause oxidant overproduction and endothelial dysfunction. In diabetic kidney disease pathogenesis, the overproduction of reactive oxygen species is the common mediator of several hyperglycemia-activated pathways [11]. Geetha et al. reported that there is a weak positive correlation of microalbuminuria with blood sugar levels, duration, and SBP [15]. If the microalbuminuria condition remains untreated, it can lead to further renal damage.

eGFR level in metformin group was lower than metforminsulfonylurea groups $(\mathrm{p}=0.018)$. Hyperfiltration, defined by eGFR $\geq 90 \mathrm{~mL} / \mathrm{min} / 1.73 \mathrm{~m}^{2}$, was more frequent in metformin-sulfonylurea group, significantly $(\mathrm{p}=0.029)$. Renal function remained seems normal but was probably beginning to suffer damage [16]. eGFR elevation in patients taking a metformin-sulfonylurea combination does not indicate improved renal function over that of patients taking metformin. Rather, it indicates that patients taking a metformin-sulfonylurea combination with normal or elevated eGFR had begun to experience early renal impairment (CKD Stage 1 or 2), characterized primarily by microalbuminuria.

\section{CONCLUSION}

Metformin monotherapy was associated with a lower frequency of hyperfiltration and lower UACR level compared to metforminsulfonylurea combination.

\section{ACKNOWLEDGMENT}

This study was supported by PITTA Grant, University of Indonesia for the financial support and assistance.

\section{CONFLICTS OF INTEREST}

All authors have none to declare.

\section{REFERENCES}

1. Giacco F, Brownlee M. Pathogenesis of microvascular complications. Textbook of Diabetes. $4^{\text {th }}$ ed. United States: Blackwell Publishing Ltd.; 2010. p. 553-74

2. Simatupang TA, Wijaya S. Nefropati pada pasien diabetes mellitus. Dam J Med 2010;9:30-7.

3. Gross J, de Azevedo M, Silveiro S, Canani L, Caramori M, Zelmanovitz T. Diabetic nephropathy: Diagnosis, prevention, and treatment. Diab Care 2004;28:164-76.

4. Sauriasari R, Andriany R, Sekar A. Comparison of antioxidative effect of metformin and combination of metformin-sulfonylurea in type 2 diabetes mellitus patients. J Young Pharm 2017;9:s39-42.

5. Nasri H, Baradaran A, Reza AM, Mardani S, Momeni A, RafieianKopaei M. Bright renoprotective properties of metformin beyond blood glucose regulatory effects. Iran J Kidney Dis 2013;7:423-8.

6. Sauriasari R, Andrajati R, Azizahwati, Dharmeizar, Saputri DA, Muris RU, et al. Marker of lipid peroxidation related to diabetic nephropathy in Indonesian type 2 diabetes mellitus patients. Diabetes Res Clin Pract 2015;108:193-200.

7. Hung AM, Roumie CL, Greevy RA, Liu X, Grijalva CG, Murff HJ, et al. Kidney function decline in metformin versus sulfonylurea initiators: Assessment of time-dependent contribution of weight, blood pressure, and glycemic control. Pharmacoepidemiol Drug Saf 2013;22:623-31.

8. Hippisley-Cox J, Coupland C. Diabetes treatments and risk of amputation, blindness, severe kidney failure, hyperglycaemia, and hypoglycaemia: Open cohort study in primary care. BMJ 2016;352:i1450

9. World Health Organization. Global Database on Body Mass Index. Available from: http://www.apps.who.int/bmi/index. jsp?introPage $=$ intro 3.html. [Last accessed on 2019 July 20].

10. Cheung B, Li C. Diabetes and hypertension: Is there a common metabolic pathway? Curr Atherscler Rep 2012;14:160-6.

11. Hsu CC, Chang HY, Huang MC, Hwang SJ, Yang YC, Lee YS, et al. $\mathrm{HbA1c}$ variability is associated with microalbuminuria development in type 2 diabetes: A 7-year prospective cohort study. Diabetologia 2012;55:3163-72.

12. American Diabetes Association. Standards of Medical Care in Diabetes-2017. Available from: http://www.care.diabetesjournals.org/ content/diacare/suppl/2016/12/15/40.Supplement_1.DC1/DC_40_S1_ final.pdf. [Last accessed on 2019 July 20].

13. Sauriasari R, Mahani R, Sekar A. Urinary hydrogen peroxide and renal function parameter of type 2 diabetes mellitus patients consuming metformin and metformin-sulfonylurea. J Young Pharm 2017;9:s5-8.

14. Kumar DA, Arivazhagan R, Sudhandiran G, Sangeetha R, Swaminathan S. The effect of metformin monotherapy on biochemical parameters associated with diabetes mellitus, kidney, cardiac, liver, thyroid, and reproductive organ functions in pre-and post-menopause women with type 2 diabetes mellitus. Asian J Pharm Clin Res 2018;11:84-91

15. Geetha $P$, Shanmugasundaram P. Correlation of microalbuminuria with age, duration, glycated hemoglobin, blood sugar levels, blood pressure and renal parameters of type 2 diabetes patients. Asian J Pharm Clin Res 2017;10:397-400.

16. Middleton RJ, Foley RN, Hegarty J, Cheung CM, McElduff P, Gibson JM, et al. The unrecognized prevalence of chronic kidney disease in diabetes. Nephrol Dial Transplant 2006;21:88-92. 